Received: 07/08/2018

Revision: $11 / 11 / 2018$

Accepted: $16 / 11 / 2018$

OnlineFirst: $15 / 12 / 2018$

\title{
A Path Analysis of Typical Intellectual Engagement, Learning Style and Preference for Assessment
}

\section{Maleki Ali Reza}

MA Student, Islamic Azad University, Mashhad Branch, alireza.m.1373@gmail.com

\section{Mitra Zeraatpishe}

Asst. Prof., corresponding author, Islamic Azad University, Mashhad Branch, Corresponding: mitra.zeraatpishe@yahoo.com \& zeraatpisheh4491@mshdiau.ac.ir

\author{
Akram Faravani \\ Asst. Prof., Islamic Azad University, Mashhad Branch,afaravai@yahoo.com
}

One of the most significant issues in the process of teaching and learning is to consider students' individual differences. The aim of this study was to investigate the interrelationships among Iranian EFL Learners' Typical Intellectual Engagement, Learning Style and Preference for Assessment Methods. The sample included 200 English learners majoring in TEFL (Teaching English as a Foreign Language) from 3 different universities in Mashhad, Iran. To this end, three questionnaires; Typical Intellectual Engagement questionnaire, learning style inventory, and preference for assessment methods questionnaire were administered. The interrelationships among all variables were examined using path analysis. The model was fitted after some modifications. Findings revealed that Typical Intellectual Engagement was a positive and significant predictor of all four sub-factors of EFL learners' learning styles except Activist. Also, all four subfactors of EFL learners' learning styles except pragmatist were significant predictors of preference for assessment methods. Finally, the fit model showed that Typical Intellectual Engagement was a positive significant predictor of preferred assessment methods $(\mathrm{r}=.24, .22, \mathrm{p}<.05)$. This study has several implications for teachers, learners, and syllabus designers.

Keywords: individual differences, typical intellectual engagement, learning style, preference for assessment methods, path analysis

\section{INTRODUCTION}

Student's individual learning styles and preferences, their past experiences in learning language, their linguistic attitudes, their personalities, perhaps even their view on life, 
are totally different and unique to them and these are the bases of individual differences (Mccarthy, 2010). Typical Intellectual Engagement (TIE) describes a person's engagement in intellectual activity and his or her interest in and need for a profound understanding of complex issues. Individuals with high engagement receive better grades, score significantly higher on standardized ability tests (Chamorro-Premuzic, Furnham, \& Ackerman, 2006). Javadi, Mohammadi, and Akbari (2017) argued that the differences in students' thinking process and intelligence influence their learning process. Besides, Pedone (2014) stated that cognitive strategies can help students to identify their learning styles and strategies.Therefore, on the whole, Typical Intellectual Engagement (TIE) seems to be related to students' learning styles.

According to Honey and Mumford (1986), there are four learning styles: activist, theorist, reflector and pragmatist. As they believed, activists are those individuals who take more risks and seek new experiences or learning situation. On the other hand, theorists are more likely to learn through rational thinking and logically analyzing ideas. Those with a reflector learning style prefer to observe and experimenting using a wide range of sources. Finally, pragmatists prefer to learn through doing and applying practical techniques and problem-solving tasks.

According to Warn (2009), there is a significant relationship between students' learning styles for different subjects and their orientations for different kinds of assessment methods. In fact, different people learn in different ways. Some learners are used to processing experiences and knowledge sequentially, others are used to doing it randomly; some learners are highly analytical in decision making, while others use their feelings for deciding; some learners are visual-oriented; others are verbal-oriented; some learners prefer to learn in groups; others prefer to learn alone and in home, etc (Ismail, Hussain, \& Jamaluddin, 2010). Accordingly, students' learning style can play a role in their preference for assessment methods (Pantiwati, Y., \& Husamah, 2017).

Based on Chamorro-Premuzic, Furnham, and Ackerman (2006), Typical Intellectual Engagement (TIE) is correlated with students' academic performance and their marks in different tests. Also, Schroeders, Schipolowski and Böhme (2015) issued that TIE has been proved to be correlated with students' scholastic and academic performance. This will provide a rational to show that Typical Intellectual Engagement (TIE) and preference for assessment are correlated with each other.

To provide a rationale for this proposed model, the researcher provide the following justifications gained through literature. On the whole, as mentioned by Pedone (2014); and Javadi, Mohammadi, and Akbari (2017), Typical Intellectual Engagement (TIE) seems to be related to students' learning styles. Based on Rosenberg (2011), an individual's cognitive styles can significantly predict his/her rational decision making style. So, a path can be directed from Typical Intellectual Engagement to Theorist. According to Rozencwajg and Corroyer (2005), reflective individuals who do any kind of analytic processes are cognitively mature and better compared with others. Therefore, it can be concluded that learners with a good level of Typical Intellectual Engagement are good Reflectors as well. Stadler, Becker, Gödker, Leutner, and Greiff (2015) hold 
that intelligence strongly predicts one's complex problem solving. So, it can be inferred that learners with a total typical Intellectual Engagement tend to be more Pragmatists.

Ismail, Hussain, and Jamaluddin (2010) issued that there are different kinds of learning styles and students tend to learn different things in different ways. As stated by Warn (2009), students' learning styles have effects on their assessment. Accordingly, students' learning style can play a role in their preference for assessment methods. Bazargani and Larsari (2013) found in their study that a person's reflective thinking can impact his/her performance on multiple choice tests. Hence, a path can be directed from reflector to recognition-based exam. Eventually, Wang and Lin (2015) pinpointed that there is a positive and strong association between risk-taking and students' desire in oral production items. Thereupon, a path can be directed from activist to production type of exams. . According to Wickramasinghe and Hettiarachchi (2017), the main problem lies in the fact that teachers do not develop their assessment methods based on their students' preferred assessment methods as well as their learning styles while giving exams. Assessing all of the students based on only one or two methods of assessment is a problem which can be seen widely. To tackle this problem, this study tries to show that students should be assessed via methods which are preferred by them and are in correspondence with their learning styles.

As aforementioned by some researchers (Chamorro-Premuzic, Furnham, \& Ackerman, 2006; Schroeders, Schipolowski \& Böhme, 2015), Typical Intellectual Engagement (TIE) is correlated with students' academic assessment and their marks in different tests. This provides a rational to show that Typical Intellectual Engagement (TIE) and preference for assessment are correlated with each other. So, there are significant relationships between Typical Intellectual Engagement and two total types of preferred exams. The following research question is probed in this study: Does the proposed model of associations among typical intellectual engagement, learning style, and preference for assessment show enough adequacy for the context of Iran?

\section{METHOD \\ Participants and Setting}

According to Kline (2015), at least 200 participants are needed to run a path analysis. Therefore, the sample of this study comprised 200 English learners from different universities in Mashhad, Iran, namely Islamic Azad University, Tabaran Institute of Higher Education and Toos University of Mashhad. The method through which the sample was selected was convenience sampling for the availability and manageability reasons. The sample included both males and females with different age groups ranging from young to middle aged students. Their field of study was Teaching English as a Foreign Language consisting, doing both Bachelor's and Master's degrees.

\section{Instrumentation}

In this study, three kinds of questionnaires were administered. Typical Intellectual Engagement was assessed through using a revised validated version of Wilhelm et al.'s (2003) German short scale which is a three dimensional model including reading, contemplation and intellectual curiosity. The students participating in this study 
indicated their agreement/disagreement with 18 statements on a 4-point Likert scale ranging from strongly agree to strongly disagree. The reliability of this questionnaire is 0.77 (Table 3).

The second instrument was Honey and Mumford's Learning Style Questionnaire (1986) to identify preferred learning style of the students which are activist, theorist, reflector or pragmatist. The questionnaire included 80 statements with a box in front of each statement. 20 items were allocated to each learning style. The participants were asked to place a tick in the boxes in front of the sentences if they mostly agree with that sentence. Accordingly, if they did not, they had to leave the box blank. At last, the sum of the items showed their dominant learning style. The reliability of this questionnaire is 0.82 (Table 3).

The learners' preference for different kinds of assessment methods were gathered through a self-developed questionnaire which was validated in this study through running confirmatory factor analysis, the results are displayed in Table 6. This questionnaire consisted of 7 statements which asked for learners' testing methods preference including: essay-type test, completion test, multiple choice test, cloze test, true-false test, information-gap test, and oral exam. Based on Shintani, Natsuko, Shaofeng, and Ellis (2013) essay-type, completion test, cloze test, information gap and oral exams were put into the category of production tests which the learners are asked to produce sentences effectively and reactively. On the other hand, multiple-choice or trueor-false tests were put to the category of recognition-based tests (Fazio, Agarwal, Marsh, \& Roediger, 2010). The reliability of this questionnaire was calculated to be 0.73 (Table 3).

\section{Procedure}

Collecting data started in early February, 2018 and it took almost one month. Participants answered 3 questionnaires with the total time of 25 minutes as well as giving their demographic information; i.e., name (optional), field of study, gender and age. Then, the collected data were fed into the SPSS software to calculated the normality assumptions and descriptive statistics. Then through AMOS software, a path analysis was run to verify the interrelationships among the three variables.

\section{Study Design and Analysis}

The method of this study was quantitative in nature which investigated the interrelationships among the variables within a correlational design. The interrelationships among all variables were determined by using Structural Equation Modeling (SEM), specifically path analysis.

\section{FINDINGS}

To check the normality of data distribution, the Kolmogorov-Smirnov test was employed. This test is used to check whether the distribution deviates from a comparable normal distribution. If the $p$-value is non-significant $(p>.05)$, we can say that the distribution of a sample is not significantly different from a normal distribution, therefore it is normal. If the $p$-value is significant $(p<.05)$ it implies that the distribution is not normal. Table 1 presents the results of the Kolmogorov-Smirnov test. 
Table 1

The Results of K-S Test

\begin{tabular}{lll}
\hline & Df & Sig. \\
\hline Learning Style & 189 & .075 \\
Typical intellectual engagement & 189 & .083 \\
Preference & 189 & .060 \\
\hline
\end{tabular}

As it can be seen, the obtained sig value for all variables is higher than .05 . Therefore, it can safely be concluded that the data is normally distributed across all the variables.

Table 2 presents descriptive statistics of all constructs of the study including the mean, standard deviation, maximum and minimum scores.

Table 2

Descriptive Statistics of all constructs

\begin{tabular}{lllllll}
\hline & & N & Minimum & Maximum & Mean & Std. Deviation \\
\hline \multirow{4}{*}{ Learning Style } & Activist & 189 & 2.00 & 19.00 & 9.74 & 3.21 \\
\cline { 2 - 7 } & Reflector & 189 & 2.00 & 20.00 & 12.73 & 3.67 \\
\cline { 2 - 7 } & Theorist & 189 & 3.00 & 19.00 & 11.73 & 3.66 \\
\cline { 2 - 7 } & Pragmatist & 189 & 2.00 & 20.00 & 11.43 & 3.39 \\
\cline { 2 - 7 } & Learning Style & 189 & 18.00 & 72.00 & 45.64 & 9.50 \\
\hline \multirow{3}{*}{ TIE } & $\begin{array}{l}\text { typical intellectual } \\
\text { engagement }\end{array}$ & 189 & 28.00 & 66.00 & 48.07 & 6.77 \\
Preference for & & & & & & \\
Assessment & Recognition-based & 189 & 3.00 & 10.00 & 8.23 & 1.58 \\
\cline { 2 - 7 } & Production-based & 189 & 8.00 & 25.00 & 16.21 & 3.78 \\
\cline { 2 - 7 } & Preference & 189 & 14.00 & 34.00 & 24.44 & 4.20 \\
\hline
\end{tabular}

The possible range of scores for all four sub-constructs of learning styles with 20 items is between 0-20 and for total learning style is between 0-80. As the results show, among four sub-constructs of learning styles, Reflector has the highest mean score (12.73), and activist has the lowest mean score (9.74). The possible range of score for Recognitionbased with 2 items is between 2 and 10, for Production-based with 5 items is between 5 and 25, and for total preference with 7 items is between 7 and 35 .

Also the reliability of the instruments utilized in the study is summarized in Table 3 which is obtained from Cronbach alpha analyses.

Table 3

Results of Cronbach Alpha Indexes After Reliability Analysis

\begin{tabular}{lll}
\hline Scale & Number of items & Cronbach alpha \\
\hline Learning Style & 80 & .82 \\
Typical intellectual engagement & 18 & .77 \\
Preference & 7 & .73 \\
\hline
\end{tabular}

As can be seen, the utilized questionnaires gained acceptable indexes of Cronbach alpha as a whole: Learning Style Scale (.82), Typical intellectual engagement Scale (.77), and Preference (.73).

This study is an attempt to find any probable interrelationships among TIE, learning style, and preference for assessment through proposing a model of associations among them. Figure 1 displays the probable paths, gained throughout the literature, for different constructs of this study. 


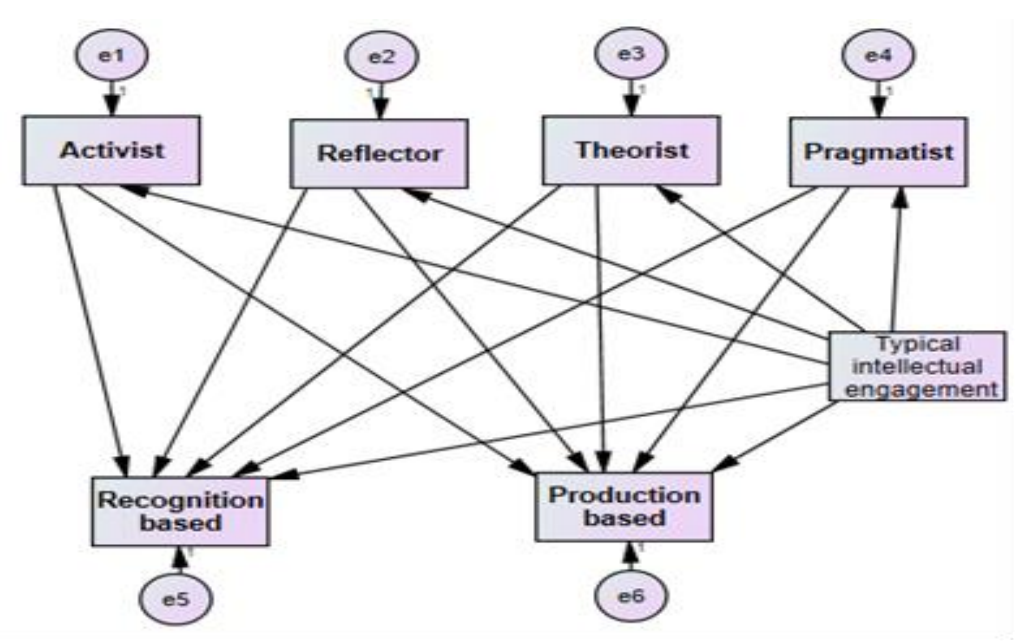

Figure 1

The proposed model for interrelationships among Typical Intellectual Engagement, learning style and preference for assessment methods

Figure 2 shows the path analysis of the relationship between Typical Intellectual Engagement, learning style and preference for assessment methods. As it shows, an estimate is displayed on each path.

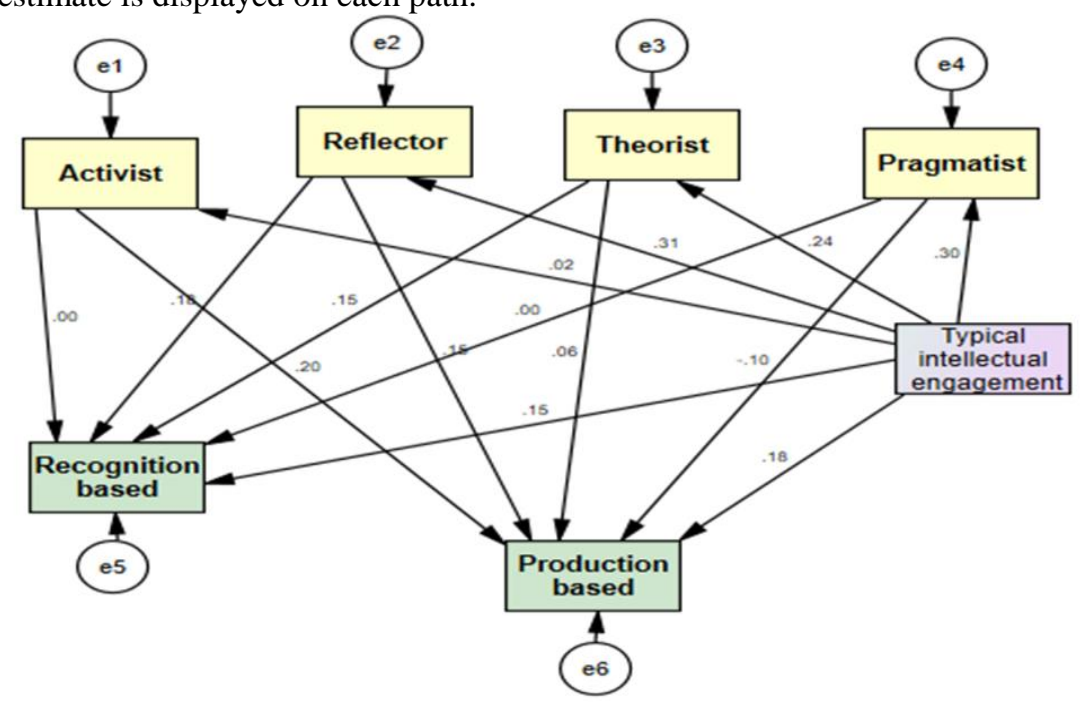

Figure 2

The path analysis of the relationship between variables before modification

As indicated in Figure 2, an estimate is displayed on each path. This standardized estimate is the standardized coefficient or beta coefficients $(\beta)$ resulting from an analysis 
carried out on independent variables that have been standardized. It explains the predictive power of the independent variable and the effect size. The closer the magnitude to 1.0 , the higher the correlation and the greater the predictive power of the variable is. Table 4 shows the goodness of fit indices before modification.

Table 4

Goodness of Fit Indices Before Modification

\begin{tabular}{llllll}
\hline & X2/df & GFI & NFI & CFI & RMSEA \\
\hline Acceptable fit & $<3$ & $>.90$ & $>.90$ & $>.90$ & $<.08$ \\
Model & 6.25 & .87 & .88 & .86 & .098 \\
\hline
\end{tabular}

As demonstrated by Table 4, (the chi-square/df ratio (6.25), RMSEA (.098), GFI (.87), NFI (.88) and CFI (.86)), all the fit indices do not lie within the acceptable fit thresholds. Therefore, the model needs some modifications. In order to modify the model, five non-significant paths were removed: 1) Activist to recognition-based ( $\beta=$ $.00, \mathrm{p}>.01), 2)$ Pragmatist to recognition-based $(\beta=.00, \mathrm{p}>.01), 3)$ Theorist to production -based $(\beta=.06, p>.01), 4)$ Pragmatist to production -based $(\beta=.10, p>.01)$, and 5) Typical Intellectual Engagement to activist $(\beta=.02, p>.01)$. After applying the modifications, the model was run again, the results of which are displayed in Table 5.

Table 5

Goodness of Fit Indices After Modification

\begin{tabular}{llllll}
\hline & X2/df & GFI & NFI & CFI & RMSEA \\
\hline Acceptable fit & $<3$ & $>.90$ & $>.90$ & $>.90$ & $<.08$ \\
Model & 2.79 & .93 & .91 & .92 & .079 \\
\hline
\end{tabular}

As demonstrated by Table 5, the chi-square/df ratio (2.79), RMSEA (.079), GFI (.93), NFI (.91) and CFI (.92), all the fit indices lie within the acceptable fit thresholds. Hence, it can be concluded that the proposed model had perfect fit with the empirical data after modification. Figure 3 shows the model after modifications.

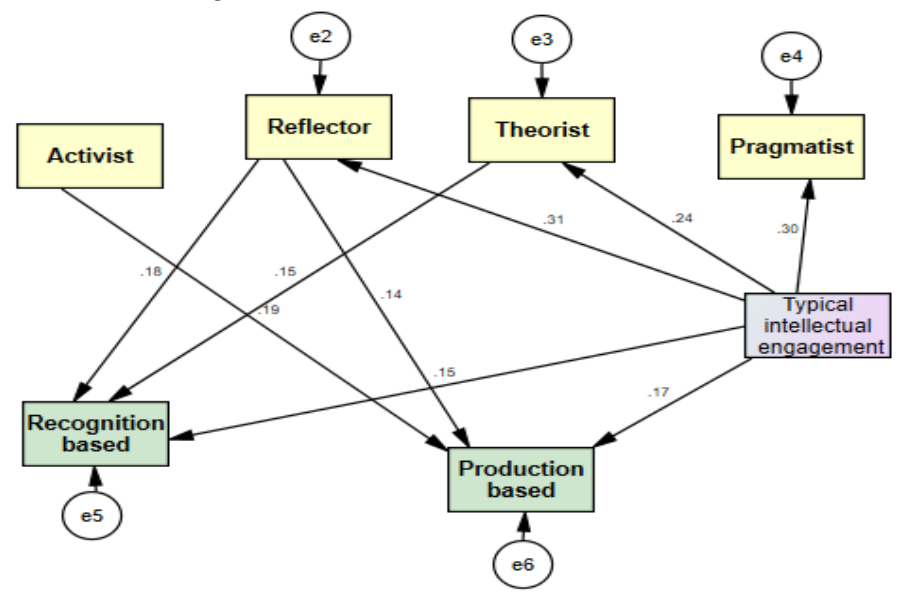

Figure 3

The model after modification 
In order to examine the validity of the preference for assessment questionnaire, Confirmatory Factor Analysis (CFA) was used. In this study, x2/df, GFI, CFI and RMSE were used. As Table 6 shows, all the goodness of fit indices are within the acceptable range. Therefore, the scale enjoyed perfect validity.

Table 6

Goodness of Fit Indices (for Validating Preference for Assessment Questionnaire)

\begin{tabular}{lllll}
\hline & $\mathrm{X} 2 / \mathrm{df}$ & GFI & CFI & RMSEA \\
\hline Acceptable fit & $<3$ & $>.90$ & $>.90$ & $<.08$ \\
Model & 2.59 & .91 & .92 & .08 \\
\hline
\end{tabular}

Goodness of fit indices can be seen in Table 6. In this study, $\chi^{2} / \mathrm{df}$, GFI, CFI and RMSEA were used. As Table 6 shows, all the goodness of fit indices are within the acceptable range. Therefore, preference for assessment questionnaire enjoyed perfect validity.

\section{DISCUSSION}

According to path analysis which was run in this study, Typical Intellectual Engagement was positively a predictor of all four sub-factors of learning styles except Activist. Findings indicated a significant relationship between Typical Intellectual Engagement and Theorist $(\mathrm{r}=.306, \mathrm{p}<.05)$. In fact, Theorist has the highest correlation with Typical Intellectual Engagement. The obtained results were according to those of Rosenberg (2011) who found that one's cognitive aspects and style were significantly predicting his/her rational decision making style. So, it seems that individuals with a good level of Typical Intellectual Engagement are more likely to make logical and rational decisions. Results showed that the relationship between Typical Intellectual Engagement and Reflector were significant $(\mathrm{r}=.24, \mathrm{p}<.05)$. The findings were consistent with what Rozencwajg and Corroyer (2005) obtained in their study. Therefore, it can be concluded that learners with a good level of Typical Intellectual Engagement are better thinkers and analyzer and enjoy pondering about aspects of a matter. Results indicated the relationship between Pragmatist and Typical Intellectual Engagement which was moderately significant $(r=.30, p<.05)$. Such a positive relationship gained in this study was in agreement with Stadler et al. (2015) who came to the conclusion that intelligence is a strong predictor of complex problem solving. So, it can be inferred that learners with a total typical Intellectual Engagement tend to be more Pragmatists and interested in problem solving tasks.

The findings demonstrated that the relationship between learners' Recognition-based preference for assessment and Theorist was positively significant $(r=.28 \mathrm{p}<.05)$. The results were in contrast with what Stanger-Hall (2012) found in her study. She came to the conclusion that there is no significant relationship between higher-level thinking such as logical reasoning and critical thinking and traditional multiple choice exams. From the researcher's point of view, the reason behind these differences in results might be the fact that students might not have an adequate knowledge of language to produce the answers in English. Another possibility is that since some of them might prefer to cheat during their exams, they were more likely to show more interest for recognition 
tests which are easier to cheat. So, they chose recognition-based exams as their dominant preferred assessments. Also, the results showed that there is a positive significant relationship between learners' Recognition-based preference for assessment and Reflector $(\mathrm{r}=.309 \mathrm{p}<.05)$. The results were in line with those of Bazargani and Larsari (2013) and what they found in their study. They claimed that one's reflective thinking or observation can influence his/her performance and preference on multiple choice items test. Therefore, it can be inferred that the learners with the dominant styles of Reflectors prefer the recognition-based exams. The relationship between learners' Production-based preference for assessment and Activist was significant $(r=.17 \mathrm{p}<.05)$. Findings were in agreement with what Wang and Lin (2015) found in their study. As they claimed, there is a positive and strong correlation between risk-taking and students' desire in oral production items. Therefore, it can be concluded that learners with the dominant styles of Activists who tend to take risks are more likely to prefer productionbased exams. Furthermore, a significant relationship between learners' Production-based preference for assessment and Reflector $(r=.16 \mathrm{p}>.05)$ was gained. Findings were in contrast with those of Rastegar and Honarmand (2016). They issued that there is no significant relationship between cloze test and reflective thinking and observation. In fact, based on the findings of this study, individuals with the dominant styles of Reflectors are interested in both recognition and production types of exams. The probable reason behind this inconsistency with the previous literature might be due to the difference in the degree of tests difficulties or some distracted factors in the test environment which might hinder the reflection. Results indicated that there is no significant relationship between learners' Production-based preference for assessment and Pragmatist ( $r=.09$ p>.05). Obtained results were in contrast with what Ghodrati, Bavandian, Moghaddam, and Attaran (2014) gained in their study. They believed that there is a high correlation between cloze type of test and elements of problem solving. In fact, based on the results of our study, learners with the dominant styles of Pragmatists show no interest for any kind of exams. This might be because the participants' proficiency level of proficiency was not controlled which might affect their performance on cloze tests.

In the present study, the relationship between EFL learners' Typical Intellectual Engagement and their Recognition-based preference for assessment were significant $(\mathrm{r}=.24 \mathrm{p}<.05)$. Also, Findings showed a significant relationship between learners' Typical Intellectual Engagement and their Production-based preference for assessment $(\mathrm{r}=.22 \mathrm{p}>.05)$. The obtained results among Typical Intellectual Engagement and two constructs of preference for assessment methods were in line with what Zahedi and Moghaddam (2016) found. According to them, different kinds of intelligences are correlated positively with performance on multiple-choice and cloze tests.

This study has several implications for teachers, syllabus designers, and material developers. By considering their students' learning style and preferred assessment type, they can improve the instructional and educational system (Donough \& Shaw, 2003). Along the same line, Tomlinson (2011) states that materials should consider different learning styles, which means that activities should be variable and should fit to all learning styles. So, the present study can be helpful to the material developers as well. 
Furthermore, Stranks (2003) shed light on the importance of considering students' learning styles for syllabus designers. He believed that tasks which contain mental activities will not suit all learners. This implies that syllabus designers should take into account the students' learning styles for grading and sequencing tasks.

\section{CONCLUSION}

This study has attempted to shed light on the interrelationships among Iranian EFL learners' Typical Intellectual Engagement, learning style and preference for assessment methods. Based on path analysis, Typical Intellectual Engagement was a positive and significant predictor of all four sub-factors of EFL learners' learning styles except Activist. Besides, all four sub-factors of EFL learners' learning styles except pragmatist were proven to be significant predictors of preference for assessment methods. At last, the fit model showed that Typical Intellectual Engagement was a positive significant predictor of both constructs of preference for assessment methods, namely recognition and production based tests.

Further research is needed to illuminate the possible interrelationship among the variables of this study and other variables which are related to learners' specific cognitive and affective factors.

\section{REFERENCES}

Arteche, A., Chamorro-Premuzic, T., Ackerman, P., \& Furnham, A. (2009). Typical intellectual engagement as a byproduct of openness, learning approaches, and self-assessed intelligence. Educational Psychology, 29(3), 357-367. doi: $10.1080 / 01443410902927833$

Bazargani, D. T., \& Larsari, V. N. (2013). Impulsivity-reflectivity, gender and performance on multiple choice items. International Journal of Language Learning and Applied Linguistics World (IJLLALW), 4(2), 194-208.

Chamorro-Premuzic, T., Furnham, A., \& Ackerman, P. L. (2006). Ability and personality correlates of general knowledge. Personality and Individual Differences, 41(3), 419-429. doi: 10.1016/j.paid.2005.11.036

Donough, J. M., \& Shaw, C. (2003). Materials and method in ELT: A Teacher's guide2nd.

Fazio, L. K., Agarwal, P. K., Marsh, E. J., \& Roediger, H. L. (2010). Memorial consequences of multiple-choice testing on immediate and delayed tests. Memory \& cognition, 38(4), 407-418. doi: 10.3758/MC.38.4.407

Ghodrati, M., Bavandian, L., Moghaddam, M. M., \& Attaran, A. (2014). On the relationship between problem-solving trait and the performance on $\mathrm{C}$-test. Theory and practice in language studies, 4(5), 1093-1100. doi:10.4304/tpls.4.5.1093-1100.

Honey, P. (1986). A manual of learning styles (Maidenhead, Honey \& Mumford). doi: $10.1177 / 135050768301400209$ 
Honey, P. (1986). A manual of learning styles (Maidenhead, Honey \& Mumford). doi: $10.1177 / 135050768301400209$

Ismail, A., Hussain, R. M. R., \& Jamaluddin, S. (2010). Assessment of students' learning styles preferences in the faculty of science, Tishreen University, Syria.Procedia-Social and Behavioral Sciences,2(2), 4087-4091. doi: 10.1016/j.sbspro.2010.03.645

Javadi, A., Mohammadi, Y., \& Akbari, N. (2017). The condition of learning styles, student engagement and its relationship with academic progress in Birjand University of Medical Sciences. Future of Medical Education Journal,7(2), 23-28. doi: 10.22038/FMEJ.2017.8910

Kline, R. B. (2015). Principles and practice of structural equation modeling. Guilford publications. ISBN: 9781462523344

McCarthy, M. (2010). Experiential learning theory: From theory to practice. Journal of Business \& Economics Research, 8(5), 131-139. doi: 10.19030/jber.v14i3.9749.

Mumford, A., \& Honey, P. (1986). Developing skills for matrix management. Industrial and Commercial Training, 18(5), 2-7. Doi:10.1108/eb004043.

Pantiwati, Y., \& Husamah (2017). Self and Peer Assessments in Active Learning Model to Increase Metacognitive Awareness and Cognitive Abilities. International Journal of Instruction, 10(4), 185-202. doi: 10.12973/iji.2017.10411a

Pedone, F. (2014). Learning styles and metacognition. In INTED2014, 8th International Technology, Education and Development Conference (1678-1687). IATEDInternational academy of technology, education and development. ISBN: 978-84-6168412-0

Rastegar, M., \& Honarmand, N. M. (2016). Field dependence/independence, impulsivity/reflectivity, gender, and cloze test performance of Iranian EFL learners: A study of relations. European Scientific Journal, ESJ, 12(8). doi: 10.19044/esj.2016.v12n8p\%25p

Rosenberg, C. (2011). Cognitive characteristics affecting rational decision making style (Master's thesis), Retrieved from https://www.duo.uio.no/bitstream/handle/10852/18102/masteroppgavexxCharlottexRose nbergxxpdf.pdf?sequence.

Rozencwajg, P., \& Corroyer, D. (2005). Cognitive processes in the reflective-impulsive cognitive style. The Journal of genetic psychology, 166(4), 451-463. doi: 10.3200/GNTP.166.4.451-466

Schroeders, U., Schipolowski, S., \& Böhme, K. (2015). Typical intellectual engagement and achievement in math and the sciences in secondary education. Learning and Individual Differences, 43, 31-38. doi: 10.1016/j.lindif.2015.08.030 
Shintani, N., Li, S., \& Ellis, R. (2013). Comprehension based versus production based grammar instruction: A meta-analysis of comparative studies. Language learning, 63(2), 296-329. doi: 10.1111/lang.12001\}

Stadler, M., Becker, N., Gödker, M., Leutner, D., \& Greiff, S. (2015). Complex problem solving and intelligence: A meta-analysis. Intelligence, 53, 92-101. doi: 10.1016/j.intell.2015.09.005

Stanger-Hall, K. F. (2012). Multiple-choice exams: an obstacle for higher-level thinking in introductory science classes. CBE-Life Sciences Education, 11(3), 294-306. doi: 10.1187/cbe.11-11-0100.

Stranks, J. (2003). Materials for the teaching of grammar. Developing materials for language teaching, 329-339. ISBN: 9781441186836

Tomlinson, B. (Ed.). (2011). Materials development in language teaching. Cambridge University Press. ISBN: 978-144-112-230-8

Wang, Y., \& Lin, Y. (2015). A study on correlation of risk-taking and the oral production of English majors in China. English Language Teaching, 8(10), 113. doi:10.5539/elt.v8n10p113

Warn, T. S. (2009). Students' learning style and their academic achievement for Taxation course-A comparison study. In 2nd International Conference of Teaching and Learning. Retrieved from https://my. laureate. net/Faculty.

Wickramasinghe, S., \& Hettiarachchi, S. (2017). Relationship among students' learning styles, assessment methods and students' performances. 3rd International Conference on Education and Distance Learning, At Sri Lanka (Online: ISSN 2424-6514).

Wilhelm, O., Schulze, R., Schmiedek, F., \& Süß, H. M. (2003). Interindividuelle unterschiede im typischen intellektuellen engagement. Diagnostica, 49(2), 49-60. doi:10.1026//0012-1924.49.2.49.

Zahedi, S., \& Moghaddam, E. M. (2016). The relationship between multiple intelligences and performance of EFL students in different forms of reading comprehension tests. Theory and Practice in Language Studies, 6(10), 1929-1939. doi: 10.17507/tpls.0610.06. 